\title{
Understanding the Underlying Neuroprotective Role of Estrogen in TBI Neuropathophysiology
}

\author{
Maria F Zamora and Sonya M Bierbower* \\ Department of Biology, William Paterson University, USA
}

*Corresponding author: Sonya M Bierbower, Department of Biology, William Paterson University, USA.

Received Date: February 19, 2020

Published Date: February 28, 2020

\section{Introduction}

TBI is a type of CNS injury that results after a blunt force is applied to the head, and it affects about 1.7 million cases in the USA every year. The more common events that lead to a TBI are vehicle collisions, domestic violence, falls, sports, and war [1]. Depending on the severity, a TBI can result in permanent disabilities, and in extreme cases, it is fatal. Some of the symptoms seen after a TBI are lumped together in what is termed PTSD. Symptoms typically include behaviors such as depression, anti-social behavior, impulsivity, and fear/anxiety. Additionally, TBI injuries have shown symptoms that are closely related to Parkinson's and Alzheimer'slike symptoms. TBI related symptoms do not occur in a short timeframe, on the contrary, these often arise months or years after the injury has occurred, making the initial assessment of injury difficult [1-3]. A TBI occurs in two phases; the first phase is known as the primary injury or the initial injury. The second phase, referred to as the secondary injury consists of cellular processes that are activated after the initial injury and can persist for hours, days, and months after the initial impact [1,4]. Cellular processes such as nitric oxide formation, inadequate blood flow, imbalance of ions, neurotoxicity, and excitotoxicity compose the secondary injury and lead to tissue death. As a consequence, secondary injury contributes to the damage by affecting a larger area than the primary injury $[4,5]$. There is currently no treatment for this type of injury; there are only preventive measures such as wearing helmets or wearing seatbelts while driving. Thus, this review paper focused on estrogens' neuroprotection mechanism on traumatic brain injury.

Estrogen hormones are present predominantly in women and are known for their role during development and sexual reproduction, specifically during oogenesis, zygote implantation, mating behavior, and development of sex characteristics. However, rising evidence suggests estrogen has additional roles throughout the body besides sexual reproduction. Estrogen stimulates and maintains structures in the brain by modulating cell size as well as dendritic length, branching, and density [6,7]. Furthermore, sex differences have been observed in the prevalence of numerous neurodegenerative diseases. In diseases such as cerebral stroke and Parkinson's, the incidence is higher in men when compared to women. In contrast, the prevalence of Alzheimer's disease and multiple sclerosis is higher in women than in men [8]. This evidence suggests that sex hormones, such as estrogen, may play a role in the onset and progression of neurodegenerative diseases. Based on this evidence, researchers have focused on the neuroprotective role of estrogen during CNS injury using both in vivo and in vitro models, and results suggest that estrogen improves injury outcome by reducing cell death $[5,9,10]$. Especially in models of traumatic brain injury (TBI), rats with a reduced level of estrogen showed a larger volume of injury when compared to rats with estrogen levels present $[5,11]$. Despite the evidence, estrogen's neuroprotective role during TBI is not yet fully understood.

\section{Discussion}

\section{The estrogen system}

Estrogen hormones are steroid hormones derived from cholesterol and consist of three different types of hormones, estrone $\left(E_{1}\right)$, estradiol $\left(E_{2}\right)$, and estriol $\left(E_{3}\right) . E_{1}$ is a weak form of estrogen and is found during post-menopause, and $\mathrm{E}_{3}$ is predominantly found in pregnant women. $E_{2}$ is found in women before menopause 
and is the most active form of estrogen hormones; thus, researchers have focused mainly on the role of $E_{2}[6,8,12]$. $E_{2}$ 's action is usually studied in terms of the classical mechanism, that consists in the secretion and release from the endocrine gland into the bloodstream, and binding to receptors in the target tissue. Some target tissues include but are not excluded from the liver, kidney, and brain $[6,8]$. There are three identified estrogen receptors (ERs), ER $\alpha, E R \beta$, and G-coupled protein ER (GPER). ER $\alpha$ and ER $\beta$ are nuclear receptors that reside primarily in the cytoplasm and upon ligand binding dimerize and translocate into the nucleus. Dimers then bind to estrogen response elements (EREs) in the DNA, where it regulates gene expression. Dimerization can occur in different combinations, homodimers (ER $\alpha$-ER $\alpha$ or ER $\beta$-ER $\beta$ ) or heterodimers $(E R \alpha-E R \beta)[8,13]$. Additionally, due to splicing variance, numerous isoforms of ER $\alpha$ and ER $\beta$ have been identified, providing insight on the possible different responses of estrogen. Evidence suggests that the expression patterns of ER isoforms may be tissue and species dependent. Also, ER isoforms differ in ligand affinity allowing an estrogen response in a dose-dependent manner and different dimerization patterns [13-15]. In contrast, GPER is a membrane-bound receptor that is involved in secondary messenger pathways and is thought to modulate gene expression indirectly [8]. Overall, the wide variety of ERs allows estrogen to activate different responses in both genomic and non-genomic mechanisms.

\section{Estrogen's neuroprotection during TBI}

After a TBI, the blood-brain barrier (BBB) is often disrupted, which results in increased brain edema, ion imbalance, and increased intracranial pressure $[16,17]$. It is believed that estrogen plays a role in the homeostasis of the brain since BBB epithelial cells express both ER $\alpha$ and ER $\beta[8,16]$. In a weight drop TBI model, intact rats showed less brain edema when compared to ovariectomized (OVX) rats. Additionally, the use of antagonists for either ER $\alpha$ or ER $\beta$ did not inhibit estrogen's effect in reducing brain edema. Only when both ERs are antagonized levels of brain edema showed similarities to OVX rats. Hence, estrogen's role in BBB permeability is carried out by both ER $\alpha$ and ER $\beta$ [17]. Estrogen has also shown to play a role in neuroinflammation by mediating microglial activation. Microglia are the first immune cells responder after microbial infections or neuronal injury in the CNS. Microglia express a variety of genes depending on its different phenotypes, ramified, $M_{1}$ and $M_{2}$ [18]. Different gene expression patterns allow microglia to have diverse functions during a TBI. Specifically, the release of cytokines and chemokines that mediate clean up and recovery mechanisms post-TBI. Additionally, surface microglia express both ER $\alpha$ and ER $\beta$, but ER $\beta$ is often express predominantly over ER $\alpha$. Estrogen has shown to reduce the production of IL-1 $\beta$, IL6, IL-17, Th1, Th17, IFN $\alpha$ and TNF $\alpha$, and induce the release of IL-10 and TGF $\beta[8,9,14,18,19]$. This role has been documented to occur through both ER $\alpha$ and ER $\beta$. Overall, evidence suggests that estrogen may play a role in the activation of microglia and modulation of inflammatory phenotypes.

\section{Conclusion}

There is a need for the identification of therapeutic targets that can aid in the decrease of tissue death post-TBI, specifically to reduce the associated symptoms that arise months to years after impact. Estrogen has shown in numerous studies that it can improve brain injury outcomes through multiple mechanisms. However, estrogen's neuroprotection mechanisms post-TBI is still not fully elucidated. The diversity in the estrogen system makes it an appropriate target for TBI's complexity. Understanding estrogen's exact mechanism of action can lead to the development of treatments that can reduce the overall injury often seen after TBI. Furthermore, the conditions in which estrogen provides neuroprotection needs to be evaluated. Understanding how and when estrogen's neuroprotection occurs can allow the development of treatment for TBI.

\section{Acknowledgement}

William Paterson University student creative research expression program (SCREP) and Department of Biology for research funding.

\section{Conflict of Interest}

The authors have no competing financial interest.

\section{References}

1. Silver JM, McAllister TW, Yudofsky SC (2011) Textbook of Traumatic Brain Injury ( $2^{\text {nd }}$ edn.), Van Haren Publishing Zaltbommel, Netherlands.

2. Langlois JA, Rutland Brown W, Wald MM (2006) The epidemiology and impact of traumatic brain injury: a brief overview. J Head Trauma Rehabil 21(5): 375-378.

3. Xiong Y, Mahmood A, Chopp M (2013) Animal models of traumatic brain injury. Nat Rev Neurosci 14(2): 128-142.

4. Werner C, Engelhard K (2007) Pathophysiology of traumatic brain injury. British Journal of Anesthesia 99(1): 4-9.

5. Roof RL, Hall ED (2000) Gender differences in acute CNS trauma and stroke: neuroprotective effects of estrogen and progesterone. J Neurotrauma 17(5): 367-388.

6. Moyes CD, Schulte PM (2015) Principles of Animal Physiology In: C O Donnell (Edt.), Integrating Physiological Systems ( $3^{\text {rd }}$ edn.), Pearson, Canada, pp. 668-699.

7. Purves D, Augustine G, Fitzpatrick D, Hall WC, LaMantia A, et al. (2018) Neuroscience. In: AS LaMantia (Edt.), The Changing Brain. Sinauer, New York, USA, pp. 551-569.

8. Duncan KA (2015) Estrogen Effects on Traumatic Brain Injury: Mechanisms of Neuroprotection and Repair ( $1^{\text {st }}$ edn.), Amsterdam University Press, Amsterdam, Netherlands.

9. Liu X, Fan XL, Zhao Y, Luo GR, Li XP, et al. (2005) Estrogen provides neuroprotection against activated microglia-induced dopaminergic neuronal injury through both estrogen receptor- $\alpha$ and estrogen receptor- $\beta$ in microglia. J Neurosci Res 81(5): 653-665.

10. Bramlett HM, Dietrich WD (2001) Neuropathological protection after traumatic brain injury in intact female rats versus males or ovariectomized females. J Neurotrauma 18(9): 891-900.

11. Green PS, Simpkins JW (2000) Neuroprotective effects of estrogens: potential mechanisms of action. Int J Dev Neurosci 18(4-5): 347-358.

12. Petrone AB, Rudy CC, Barr TL, Simpkins JW, Reed MN (2015) Neuroprotective effects of estrogen following neural injury. Estrogen 
Effects on Traumatic Brain Injury pp. 91-111.

13. Matthews J, Gustafsson JÅ (2003) Estrogen signaling: a subtle balance between ER $\alpha$ and ER $\beta$. Mol Interv 3(5): 281-292.

14. Leung YK, Mak P, Hassan S, Ho SM (2006) Estrogen receptor (ER)- $\beta$ isoforms: a key to understanding ER- $\beta$ signaling. Proc Natl Acad Sci 103(35): 13162-13167.

15. Weiser MJ, Foradori CD, Handa RJ (2008) Estrogen receptor beta in the brain: from form to function. Brain Res Rev 57(2): 309-320.

16. Asl SZ, Khaksari M, Khachki AS, Shahrokhi N, Nourizade S (2013) Contribution of estrogen receptors alpha and beta in the brain response to traumatic brain injury. J Neurosurg 119(2): 353-361.
17. Naderi V, Khaksari M, Abbasi R, Maghool F (2015) Estrogen provides neuroprotection against brain edema and blood brain barrier disruption through both estrogen receptors $\alpha$ and $\beta$ following traumatic brain injury. Iran J Basic Med Sci 18(2): 138-144.

18. Dimayuga FO, Reed JL, Carnero GA, Wang C, Dimayuga ER, et al. (2005) Estrogen and brain inflammation: effects on microglial expression of MHC, costimulatory molecules and cytokines. J Neuroimmunol 161(12): $123-136$.

19. Nissen JC (2017) Microglial function across the spectrum of age and gender. Int J Mol Sci 18(3): 561. 